\title{
Nacionalsocialismo, Shoá, memoria: Debates historiográficos
}

National-socialism, Shoah, memory: Historiographical debates

Ing. Roberto Cyjon

robertocyjons@gmail.com

Profesor invitado del Departamento de Estudios Judaicos

Universidad ORT

Uruguay

\section{Resumen}

Este trabajo aborda las problematizaciones interpretativas del surgimiento del nacionalsocialismo, la actuación del nazismo como actor político y ejecutor de la Shoá. Se inspira en la metodología historiográfica que presenta Enzo Traverso (2012), en su libro: La historia como campo de batalla. Traverso modera y debate con historiadores, quienes, a su vez, analizan dichos temas desde perspectivas diferentes. Seleccionaremos dos ejes centrales de dichos debates: el surgimiento del nacionalsocialismo y la Shoá como impacto remanente en la autorepresentación de la sociedad alemana. Y como conjetura adicional, cuán complejo resulta ser para el historiador de genocidios, mantener su objetividad. El campo de este trabajo, tiene como corte temporal al siglo XX. El objetivo final, por decantación, es posicionar las interpretaciones teleológicas, en una mirada actual de las dificultades vigentes en la historia política y social, acerca del uso de la memoria como recurso historiográfico.

Palabras clave: Nazismo - Shoá - Antisemitismo - Memoria - Subjetividad. 


\begin{abstract}
This document addresses the problematical interpretation about the rising of nationalsocialism, the actions by the nazi party as a political actor and executor of the Shoah. It is inspired in the historiographical methodology presented by Enzo Traverso (2012) in his book: History as a battlefield. Traverso both moderates and debates with different historians who, at the same time, analyze those topics from different perspectives. We will focus in two main issues central to those debates: the rising of the nationalsocialism, and the Shoah as a remaining impact on the self-representation of the German society. And as an additional assumption, how challenging it is for a historian specialized in genocides, to maintain its objectivity. The period considered for this study is the XXth century. The final goal is: to position teleological interpretations in a current view, related to the existing difficulties of political and social history, about the use of memory as a historiographical resource.
\end{abstract}

Key words: National-socialism - Shoah - Antisemitism - Memory - Subjectivity.

\title{
Introducción
}

El historiador que aborde el tema Shoá, ha de asumir un compromiso complejo con su subjetividad y afrontar el desafío de mantener una distancia profesional óptima en su trabajo. Deberá incorporar estudios filosóficos, sociológicos, económicos, entre otros, para profundizar en la comprensión del nacionalsocialismo y sus repercusiones. Los archivos escritos, fotográficos o fílmicos, como únicas fuentes primarias, podrían ser insuficientes para la historiografía moderna. El enfoque exclusivamente político, tampoco daría suficiente cuenta de las singulares problemáticas sociales que engendró el nacionalsocialismo. Parecería ser imposible dejar de lado a las víctimas y sobrevivientes de los campos ${ }^{1}$, cuyos testimonios de por sí, configuran, a su vez, dilemas para una historiografía rigurosa. Sin "memoria", seguramente se generarían

\footnotetext{
${ }^{1}$ El término "campos", aglutina diferentes centros de reclusión, desde campos de concentración hasta de exterminio.
} 
espacios condenados al vacío analítico, acerca de la comprensión de la dimensión, de un "fenómeno de la humanidad"2 como lo fue la Shoá.

El término en sí mismo es difuso, pues se trató de un proceso de exterminio, una exclusión premeditada de un colectivo específico y varios otros, con raíces antropológicas, religiosas, sexuales, de género, étnicas, ideológicas; que puso en práctica, además, mitos sostenidos por discriminaciones milenarias. Una complejidad interpretativa adicional, la configura cuestionarnos si la intención del exterminio de los judíos, atribuible al antisemitismo alemán y europeo, ha de tratarse primordialmente como una proyección abyecta del nazismo o como un apéndice ya embrionario e indivisible del mismo ${ }^{3}$.

Enzo Traverso encara estos temas a partir de una propuesta metodológica concreta. Del desglose de su historiografía y su marco teórico, así como las ópticas de otros historiadores, iremos decantando hacia una postura, que aspira plantear, con limitaciones, opciones para un horizonte interpretativo. El objetivo es comprender, sin pretensiones de juzgar ni concluir.

\section{Las cuatro reglas historiográficas propuestas por Traverso}

Traverso sostiene que en la actualidad nos hallamos en un cruce entre utopía hacia el futuro y memoria hacia el pasado. El auge de la historia global, en tanto el mundo se considera esencialmente multipolar a partir de los años 90, conlleva un requisito de comprensión, que ha de rescatar el acontecimiento y darle cabida al recurso de la memoria.

El siglo XX apareció como la edad de rupturas repentinas, fulminantes e imprevistas,

(...) el carácter masivo de la Shoá que, en tres años, pulverizó una historia secular de

\footnotetext{
${ }^{2}$ De ex profeso encerramos entre comillas el concepto: "fenómeno de la humanidad", en tanto problematización semántica de cómo calificar la Shoá. Al categorizarla como un "fenómeno" y perteneciente a la "humanidad", no queda reducida exclusivamente a los judíos.

${ }^{3}$ Jean François Lyotard resumió la siguiente reflexión al respecto: “(...) lo más real de los judíos reales, es que Europa, por lo menos, no sabe qué hacer con ellos: cristiana, exige su conversión; monárquica, los expulsa; republicana, los integra; nazi, los extermina. 'Los judíos' son el objeto del 'no ha lugar' por el que los judíos, en particular, son golpeados realmente". Lyotard, J.F. (1995). Heidegger y "los judíos". Buenos Aires: La Marca, reseña del texto.
} 
emancipación, asimilación e integración de los judíos en el seno de las sociedades europeas, pone en cuestión los paradigmas de la historia estructural. (Traverso, 2012, pp.17-18).

El autor tipifica cuatro reglas historiográficas: contextualización, historicismo, comparatismo y conceptualización. De esa forma, considera posible ubicar a los acontecimientos en su dimensión temporal, marco social y paisaje mental de época. Entrar y salir de los acontecimientos, en forma diacrónica, lo cual habilita a captar sus transformaciones en clave de larga duración. Comparar los hechos en su fenomenología, para poder comprenderlos mejor y, finalmente, disecar lo real de lo abstracto. Este aparato historiográfico, permite considerar tanto la narrativa de los vencedores, narradores habituales de la historia, como rescatar la voz de las víctimas. En principio, ausentes, pero actores preponderantes de los episodios del totalitarismo germano y europeo, acallados precisamente, por constituir un tendal, varias veces millonario, de victimas de masacres fulminantes.

Focalizaremos en las versiones que Traverso analiza de George Mosse, Martin Broszat y Saúl Friedländer. Historiadores que pretenden explicar el surgimiento del nacionalsocialismo, la transformación de la sociedad alemana, su inmersión dentro de un "tipo ideal" como el nazismo, y los complejos dilemas intelectuales y morales en que sumió a los alemanes con el devenir del tiempo. Trámite difícil de abordar, sin detenerse en las tensiones entre historia y memoria, y la problematización de hacerlo con la objetividad historiográfica necesaria, sin sucumbir ante la subjetividad. Las inquietudes, ópticas personales y conceptuales del historiador, lo involucran como un actor más, en la traducción de "aquel" pasado a "este" presente. Siendo ambos dinámicos y definiéndose en reconfiguración constante, se trata de conceptos que exigen amplitud intelectual.

\section{Fascismo en diferentes perspectivas}

Es necesario darle cierto rigor historiográfico a términos como fascismo y nazismo, porque difieren entre sí. Si bien por derivación, se utiliza indistintamente al fascismo 
para referirse a otros totalitarismos surgidos en el período de entreguerras y posteriormente a la Segunda Guerra Mundial. El fascismo es un movimiento político de origen italiano, de comienzos incipientes del siglo $\mathrm{XX}$, que se consolida en primera instancia, durante el año 1914, como tipo ideal emergente de un partido político con bases intelectuales y de acción política, que define un líder omnipresente el cual lleva adelante proclamas bélicas, de un Estado absolutista, antidemocrático e imperialista.

Asimismo, el estalinismo, con sus diferencias de acción, origen social, ideológico y espacial, se configurará en un modelo totalitario. El franquismo español, régimen de ultraderechas y católico, que combatió a la Segunda República democráticamente elegida, generando una cruel guerra fratricida, que también incluyó brigadas internacionales, suele tildarse de fascista. El nazismo, totalitario y con puntos de encuentro conceptuales e históricos con el fascismo italiano -y de acciones políticas comunes de coyunturas y contextos historiográficos, también con el estalinismo y el franquismo-, se diferencia de todos ellos, fundamental y principalmente, por su teoría pseudo científica acerca de "un hombre ario superior" en contraposición a otros seres "subhumanos". Esa característica sería la que le diese el lamentable papel que ocupa el Holocausto en la historia mundial.

El antisemitismo no es exclusivo de los nazis, pero copartícipes al extremo de exterminio al que éstos lo llevaron, solo se han encontrado dentro de los países europeos bajo su dominación. La historiografía en tal sentido, es muy amplia. Para el postulado que emitimos, y la intensión de describir sucintamente el fascismo italiano, consideraremos a los historiadores Zeev Sternhell y Emilio Gentile. Sus diferentes ópticas, complementan una razonable comprensión del concepto.

Sternhell (1994) en su libro El nacimiento de la ideología fascista, destaca la particular interacción entre cultura y política, que diera origen al fascismo italiano desde los comienzos del siglo XX. Desarrolla la influencia que tuvo la ideología del sindicalismo revolucionario sorelista francés, en Italia, y el devenir de un repertorio de actores políticos italianos relevantes y sus movilizaciones sociales - explicitando las diferencias regionales entre el Norte (más industrializado) y el Sur (menos desarrollado)-, como 
fermento de lo que se convertiría en el Partido Nacional Fascista. No comulga con las ideas que suponen al fascismo como "un paréntesis" en la historia contemporánea, o "una infección" de un "período de decadencia de la libertad", sino como parte integral de la historia de la cultura europea ${ }^{4}$. Justifica la diferencia trascendental con el nazismo, además de su "determinismo biológico" (Sternhell, 1994, pp.1-3), por un argumento de estricta periodización: en Italia, las leyes raciales no se promulgaron hasta 1938.

La posición política que adoptaron los sindicalistas revolucionarios italianos, implicaba agrupar a las masas populares del Sur, las más numerosas, con el proletariado industrial del Norte, lo cual permitiría organizar a la masa obrera en "sindicatos de combate" (Sternhell, 1994, p.195), que pudieran, llegado el momento, confiscar los procesos de producción en manos de la burguesía. Hacia 1910, los nacionalistas y sindicalistas revolucionarios italianos, concordaron en que la democracia liberal había fracasado y se había convertido en "una enfermedad" (p.195), cuya única alternativa para neutralizarla, sería la guerra.

Pero ello implicaba un dilema. Los nacionalistas valoraban al ejército como una institución "tangible y arraigada" en el Estado; Estado, éste, que según los revolucionarios, oprimía a los trabajadores. Si la clase obrera "se negase a formar filas", sostenían, evitarían la guerra en Europa; razón que coincidía con una visión solidaria del socialismo internacionalista por sobre las naciones. La tensión entre nación y guerra, enfrentados a sindicalismo o socialismo, decantaría finalmente, en una respuesta más belicista de: "nacionalismo populista" (Sternhell, 1994, p.206).

En el ínterin se proclamaron numerosas huelgas generales como acciones de fuerza, surgieron agrupaciones sindicales con diferentes matices en sus estrategias de acción, las cuales demostraron tener capacidad de grandes convocatorias. Los lideres más prominentes de dichas corrientes, intentaron trazar puentes entre un "sindicalismo revolucionario" y un "nacionalismo radical" (Sternhell, 1994, pp.202-209). El 7 de

\footnotetext{
${ }^{4}$ Sternhell es un historiador que interpretó al fascismo a partir de los movimientos reaccionarios nacionalistas franceses de finales del siglo XIX. Parte del affaire Dreyfus, referente a un capitán judío quien fuese acusado falsamente de espionaje en 1894, y concluye con la ocupación nazi y el gobierno colaboracionista de Vichy a partir de 1940 y los años posteriores. Abordar su historiografía, desbordaría los alcances del presente trabajo.
} 
junio de 1914, en Villa Rossa -Ancona- una manifestación antimilitarista desafió al partido republicano, referente político local y, fruto de la represión policial, se aglutinaron los principales sindicatos y el partido socialista, en aras de una huelga nacional. Mussolini encabezó en Milán el mayor contingente huelguista, en un contexto de comienzos de la Gran Guerra - que luego habría de denominarse Primera Guerra Mundial-, en que cundió la desorientación general, e Italia, por su problemática interna, no lograría aún aliarse con Inglaterra y Francia contra los Imperios Prusianos y AustroHúngaro. De esa situación caótica, surge el Fascio rivoluzionario d'azione internacionalista cuyo líder será Benito Mussolini.

Las tensiones conceptuales entre nación, militarismo, sindicalismo nacional y nacionalismo radical, no se resolverían durante los años de guerra. Será recién el 23 de marzo de 1919, el día en que Mussolini funde el Movimiento Fascista en Milán, el cual las atenuaría; tornándose violento y reaccionario, en conjunción con los sectores agrícolas del Sur y el sindicalismo nacional. En los años 1920 a 1922, el fascismo italiano se terminaría de consolidar. (Sternhell, 1994)

Adjuntamos al relevamiento historiográfico de Sternhell, el de Emilio Gentile (2001), basándonos en su libro La vía italiana al totalitarismo: Partido y Estado en el régimen fascista. Gentile comienza su corte temporal en 1919 y lo proyecta inicialmente hasta los años treinta, bajo una perspectiva exclusivamente italiana. Nos es utilitaria, en tanto se puede apreciar una visión de integración más problematizada socialmente y sobre todo, expansionista, lo cual explicaría un punto de encuentro -si no de "fusión"-, con las características totalitarias del nacionalsocialismo.

Gentile (2001, p.40) explica que el Partido Nacional Fascista (en adelante PNF), a posteriori de la reunión de marzo de 1919, se conformó en el Congreso de noviembre 1921 en Roma. En esos momentos "no hubo en el fascismo un proceso de sedimentación y de fusión entre las múltiples realidades -locales, sociales, psicológicas, políticas e ideológicas- que confluyeron en el nuevo Partido”. Y continúa explicando, que una vez aglutinado bajo "el prestigio personal de un hombre", recién entonces se encontró frente al país, con responsabilidades de gobierno. Hubieron de transcurrir más 
años aún, hasta que los observadores interpretaran al "escuadrismo", como una auténtica novedad del Partido Fascista y no como un "residuo de la guerra, un conjunto de barras armadas a sueldo de los propietarios rurales o una modalidad contingente de lucha política".

Éstos expresaban: “un fenómeno social (...) antiliberal, y potencialmente totalitario (...) con el fin de conmocionar al Estado liberal y subvertirlo desde su interior" (Gentile, 2001, p.41). Entre estas ponderaciones se manejaba políticamente el Duce, sin que su revolución se terminase de configurar en Estado-nación. Lo que no lograba resolverse, era el conflicto social entre dos dimensiones antagónicas: la pequeña burguesía creía en soluciones revolucionarias y la gran burguesía aspiraba a un Estado autoritario, pero constitucional. El PNF logró articular esas disidencias, gradualmente y con dificultad, mediante un "agnosticismo ideológico" que incorporó "estratos más amplios de la burguesía conservadora, al aparato estatal" (Gentile, 2001, p.45).

De acuerdo con Gentile ( 2001, p.47) esta jerarquía primigenia, de "partido milicia" u organización armada, se "terminaría de transformar en dictadura" en noviembre de 1921, aplastando al Estado y toda forma de derechos políticos y civiles; un Estado fascista que no admitiría oposición política alguna. Ya en ese entonces, en Europa se hacía sentir un espíritu totalitario antiliberal, orientado en proyección con el fascismo italiano ${ }^{5}$. Habría coincidencias historiográficas, según Gentile, en que el PNF no alcanzaba aún una homogeneidad definida.

Entre los años 1926 y 1927, el PNF se habría transformado en estos términos: “(...) En todas las federaciones fascistas había: 1. absoluta predominancia política de los productores industriales y rurales, 2. predominancia cuantitativa de sectores medios, 3 . una cantidad sumamente acotada de obreros industriales y jornaleros agrícolas. (...)". (Gentile, 2001, p.47). Bien podría considerarse aún al fascismo como fragmentado en "muchos fascismos" cada uno con sus particularidades. En lo que no habría dudas historiográficas, es en el prestigio y magnetismo del Duce, quien mantenía unida a la totalidad de las divergencias internas y se iba configurando y representando en un mito.

\footnotetext{
${ }^{5}$ En Alemania, Hitler daría su primer fallido golpe de Estado en 1923.
} 
Para 1929, el PNF había adquirido jerarquía de "régimen”, una dictadura que: “(...) se desarrollaba como un nuevo sistema político y aspiraba a perpetuarse y expandirse" (p.51).

Traverso (2012) indaga entre sus pares de diálogo, dentro de su campo historiográfico, acerca de qué es el fascismo, refiriéndose al nacionalsocialismo. Parte de una premisa razonablemente compartida, que el fascismo fue esencialmente: una revolución, una ideología, una visión de mundo y una cultura, todas ellas expresiones concebidas desde la derecha. Sus objetivos centrales, pueden ser categorizados como la intención de construir un mundo nuevo, una ideología alternativa a partir de un nacionalsocialismo que rechazaba al marxismo, al conservadurismo y al liberalismo; una visión histórica moderna, que abarcaba también a un "hombre nuevo", si bien supresora de los límites entre lo público y lo privado. ${ }^{6}$

Resalta específicamente, que dichos postulados no ubican al fascismo como una cultura contraria a toda jerarquización previa, sino como coherente, original e incluso armónica. El fascismo, aspiraba a combatir la "degeneración”, en que habían caído las sociedades de época. Degeneración como antítesis de la "normalidad burguesa", estética, física y moral. Lo lograría reformulando un pasado mítico y romántico, exaltando la virilidad, generando emblemas que mejorasen la nación. Ello implicaba reformular "la alteridad". Algunos colectivos lo debían y podrían alcanzar "regenerándose", como ser: la juventud, los obreros, las mujeres, los campesinos rurales e incluso la academia. Contaban con herramientas para ello: el deporte en las más diversas expresiones, las asociaciones sociales de gimnastas y coros, la lealtad a un líder súper carismático que condujese a las masas (Traverso, 2012).

Otros colectivos estaban excluidos de dichas oportunidades: los judíos, gitanos, homosexuales, los delincuentes y criminales; tampoco los subversivos izquierdas,

\footnotetext{
${ }^{6}$ Federico Finchelstein (citado por Traverso en nota al pie $\mathrm{n}^{0}$ 1, p.105), sintetiza una definición coincidente y ampliada: "El fascismo es una ideología política que incluyó el totalitarismo, el terrorismo de estado, el imperialismo, el racismo, y en el caso de Alemania, el genocidio más extremo del siglo pasado: el Holocausto (...) La ideología contraria a la Ilustración, dio origen al fascismo (...) una consecuencia extrema de la Ilustración, al comunismo soviético". Fichelstein, F. (2010). Fascismo trasatlántico: Ideología, violencia y sacralidad en Argentina y en Italia, 1919-1945. Buenos Aires: Fondo de Cultura Económica, pp. 41- 42.
} 
comunistas, socialistas o anarquistas. Para todos ellos, con diferentes acciones, se aplicarían estrategias que irían desde la represión hasta la muerte. El nazismo, incluyó hasta categorías médicas y antropológicas, para librarse, concretamente, de discapacitados, homosexuales, gitanos y judíos. Se basaron en conceptos y acciones como la biología racial y la eugenesia.

En particular George Mosse, en su libro La nacionalización de las masas, suscribe una visión del nacionalsocialismo, partiendo de las siguientes premisas: la principal innovación del nacionalsocialismo fue la invención de un estilo político nuevo, que convirtió a los actos políticos en la dramatización de nuevos mitos y cultos. Fue en realidad el clímax de una nueva perspectiva, basada en una idea creciente del siglo XVIII: la soberanía popular, que deriva en "voluntad general", la cual se convierte a su vez en una "religión secular" (Mosse, 1975, pp.15-16).

El nacionalsocialismo germano pretendió que el pueblo participara activamente en la mística nacional, a través de ritos, fiestas y símbolos. Se debía incorporar lo estético y artístico, como la materialización que proporcionaría al pueblo su identidad. La estética y lo monumental serían instrumentales a dicha forma de autoexpresión. El estilo lograría una transformación dramática, y la belleza unificaría al orden con la jerarquía y una nueva "plenitud del mundo" (Mosse, 1975, p.29).

Esta belleza se remontaba a la Grecia y Roma milenarias, su mitología, estatuas y arquitectura. En forma complementaria operaría el cristianismo. Tanto el católico, que aportó la grandiosidad de las catedrales, como el pietismo, el cual con similar eficacia, sugirió un recogimiento interno más austero: "la patria está dentro de ti, es un espacio sagrado (...)" (Mosse, 1975, p.29). Conducta, espíritu, grupo, santidad tanto cristiana como secular, dieron su fruto en el florecimiento del Tercer Reich.

Mosse (1975) es solvente al sostener el movimiento de masas nacionalsocialista, como un verdadero movimiento fermental de masas. Un régimen totalitario que a todos integró con filosofía mística y dureza de acero. Todo y todos estaban incluidos e institucionalizados en su mega Estado. Un volk con espíritu y acción de volk (p.91), 
subordinado al aparato nazi ideológico, burocrático y militar en toda su dimensión, dentro y fuera de fronteras. Mosse subestimaba incluso a la propaganda nazi, en lo referente a sus consignas. Consideraba que eran más efectistas los discursos contundentes, de frases breves, actuaciones intensas e inmersas en escenografias grandiosas, que su propio contenido.

Traverso (2012, pp.113-114) amplía ciertas dimensiones de los aspectos culturales que cita Mosse, en tanto también adjetiva al "romanticismo" de Joseph Goebbels, como "de acero". El ministro de propaganda nazi "quería unir la belleza natural de los bosques germánicos, con la potencia industrial de las fábricas Krupp”. Visto el nazismo como "una metamorfosis del pesimismo cultural del siglo XIX", hacia un "modernismo reaccionario", éste reactivaría la tradición conservadora, regeneraría la nación, su faz imperialista y al Estado totalitario ${ }^{7}$. En contraposición a la visión de Mosse, afín a un "modernismo fascista" o "modernidad totalitaria".

Otra problematización se inscribe en los contenidos racistas y judeofóbicos de los discursos de Hitler y los eficientes recursos propagandísticos que tuvo el régimen ${ }^{8}$. Ello precipita a una de las discusiones centrales que pretendemos resaltar: si el antisemitismo y la pseudociencia racial que llevó al Holocausto, debieran considerarse entroncadas en la concepción político programática del nacionalsocialismo o como una resultante del devenir de los acontecimientos.

Peter Fritzsche (1998), en su libro De alemanes a nazis, acota el campo temporal de su tesis entre 1914 y 1933, a diferencia de Mosse que estudia al nacionalsocialismo bajo una metodología de larga duración. Utiliza al igual que él, un correlato fotográfico de

\footnotetext{
${ }^{7}$ Esta perspectiva se acerca más a la descripción del fascismo de Finchelstein.

8 "Mein Kampf-Mi Lucha-, fue un libro escrito por Adolf Hitler en 1924 mientras estaba en prisión. De acuerdo a su introducción, el propósito de Hitler era presentar sus objetivos y filosofía: la superioridad de la raza aria, el plan para lograr el dominio mundial de los arios y la culpabilidad de los judíos como los destructores del mundo. Fue escrito en dos volúmenes. El primero, denominado Eine Abrechnung (Cancelación de Cuentas), fue publicado en 1925. El segundo, Die Nationalsozialistische Bewegung (El Movimiento Nacional Socialista) apareció en 1926. A partir de 1930 se combinaron en un solo libro. A pesar de no estar muy bien escrito, M.K. tuvo un éxito impresionante. Para 1939 se habían vendido 5.200.000 copias y había sido traducido a once idiomas; en 1945 se habían publicado 10.000 .000 de ejemplares y traducido a dieciséis idiomas". Yad Vashem. (2004). Enciclopedia del Holocausto. Jerusalén. Nativ Ediciones, p.347.
} 
memoria testimonial y de narración. Los alemanes según Fritzche, "se volvieron nazis porque así lo desearon" (Fritzche, 1998, p.24). Por una parte optimistas, entusiasmados, participativos y con vocación de sacrificio y, por otra, motivados por medios violentos que los involucraron en hechos serios y horrorosos.

También vincula su pensamiento con Mosse. Resume Frizche que en 1933 a nadie le resultaba difícil imaginar el futuro brutal de los judíos; pero que, no obstante, la campaña nazi no incluyó específicamente en su agenda la cuestión judía. Sí estimuló el nacionalismo étnico alemán, para lograr el bienestar nacional. Coincide en parte con Mosse, en la asepsia con que aborda el Holocausto. En cambio Hanna Arendt, presenta reflexiones diferenciadas de Mosse, en cuanto a lo que subyacía en la mentalidad de la época. Arendt (1963) también se involucró en el desempeño de las masas germanas e interpretó específicamente a la banalidad. Esa "cosa vulgar" que los alemanes pretendieron derruir mediante la belleza como plataforma de monumentalidad, culto, mitología y religión secular. Utilitarios a la elevación espiritual de una nueva política y un nuevo ser humano masificado por el Estado. Si bien llegaron a construir el mayúsculo imperio nazi, la historiadora lo jerarquiza como una "tragedia" que emblematizó la "banalidad del mal". Producto de la ciega "obediencia debida" a la burocracia férrea e irresponsable, carente de los mínimos resquicios morales dentro su monolítica normativa, ${ }^{9}$ a que dieron lugar las masas electoras del nacionalsocialismo, por vía democrática. ${ }^{10}$

Traverso, por su parte, le rebate a Mosse, el hecho que subestima una característica fundamental del fascismo, como lo fue el anticomunismo. Más aún, Traverso agrega que Mosse omite consideraciones que el fascismo contrapuso con la Ilustración, en un conflicto radical; negó todos los valores de la Revolución Francesa: libertad, igualdad, derechos humanos. A su vez, le critica otro silencio clave en su historiografia: la ausencia de la violencia en sus reflexiones. Ésta nunca se ubica en el centro de su

\footnotetext{
${ }^{9}$ Ver Arendt, H. (1963). Eichmann en Jerusalén. Barcelona: de Bolsillo. Capítulo 8: Los deberes de un ciudadano cumplidor de la ley.

10 "El departamento de la oficina central de las SS encargado de la destrucción de los judíos europeos, se denominaba: 'Sección de Administración y Economía'. Si prescindimos de la gigantesca magnitud del oprobio moral, esta actividad no difería de las otras actividades organizadas, concebidas, controladas y supervisadas, como secciones administrativas y económicas 'normales", Bauman, Z. (2010). Modernidad y Holocausto. Madrid: Sequitur.p.35.
} 
análisis. Traverso se identifica con otros críticos de Mosse, que si bien respetan la construcción cultural erudita del historiador, para él parecería ser que los campos de exterminio no fueron más que un aspecto técnico del nazismo. En tanto a su regla de historicismo, Traverso se adhiere al reconocimiento unánime del papel de pionero que prestigia a Mosse, sin dejar de criticarle que su obra, al centrarse en la dimensión cultural y simbólica del fascismo, lo despolitizó en tanto objeto de memoria. Su versión sofisticada en el plano cultural y social, no distinguió cualitativamente el diagnostico posterior a la guerra. Es dable coincidir con Traverso (2012), en que no ver a la historia, desde la perspectiva de los hechos "ya acontecidos", es insostenible después del Holocausto.

Se tornaría, pues, imperioso, recurrir a la memoria para un ajuste de comprensión del nazismo alemán. Tanto por lo dramático que resultó ser para sus víctimas durante la guerra, como para la propia sociedad alemana postguerra, conceptualizada también desde su uso, o no, de la memoria. Los alemanes padecieron, o quizás padezcan aún, los efectos de una tensión sustantiva entre la transición del retorno a un régimen democrático, posterior a la guerra, y la convivencia con las rémoras traumáticas del pasado nazi.

\section{Shoá y otros genocidios}

Traverso (2012, p.185) señala que el antisemitismo configura un conjunto de representaciones acerca de un imaginario, que estigmatizan a un colectivo entero. El antisemitismo es más que un discurso o una ideología. El nazismo modernizó dicho prejuicio y lo configuró como un "código cultural". Exacerbada tal discriminación desde arriba, Hitler impuso que la sociedad germana se repliegue a sí misma como una sociedad "de exclusión", en la cual la clave de "ser alemán" consistía en "no ser judío". Más allá de los estamentos darwinianos, por los cuales se mezclaron teorías clasificatorias de hombres arios superiores y otros subhumanos, Hitler les agregó postulados políticos. Al judío se le identificó con todos aquellas ideologías y corrientes políticas enemigas del nacionalsocialismo: liberalismo, democracia, marxismo; en síntesis: la combinación ideal y abarcativa, para una exclusión "radical". A tal aparato conceptual del nazismo, Saúl Friedländer, referido por Traverso $(2012$, p.185) lo 
cataloga como: "antisemitismo redentor" (...) el cual a diferencia del antisemitismo tradicional, que transforma al judío en un chivo expiatorio, este antisemitismo, deja de actuar como un código cultural, para transformarse en una política de exterminio".

El pensador entiende que comparar genocidios, significa comparar rupturas de las normas sociales y políticas en los momentos de graves crisis y de guerra. La Shoá en particular, viró de ser un aspecto marginal de la guerra, para transformarse en un su centro y con una unicidad singular. No obstante, Traverso (2012) desarrolla un diálogo con otros historiadores como Aimé Césaire, quien considera que "el nazismo no fue más que una pequeña reproducción de las violencias coloniales perpetradas por los europeos durante siglos"11 (189-191). Arendt, citada por Traverso (2012), al analizar las masacres perpetradas por los británicos en África, y la consideración del genocidio armenio, entre otros, sustenta las comparaciones y los rasgos de similitudes genocidas. Friedländer, referido por Traverso (2012, p.188) también dialoga con Arendt y comparte con ella, que "los nazis se habían subrogado el derecho de decidir quién debe y quien no debe vivir en este planeta". Pero sostiene que dicho límite ha sido alcanzado solo una vez en la historia moderna.

Traverso (2012) se posiciona en un análisis de la cultura europea, que conlleva, según su opinión, a que Europa actuase en forma similar con "el judío" y con "el indígena". Destaca igualmente, como un argumento real, que las masacres coloniales presentan un carácter instrumental ausente en el Holocausto, pues la exterminación de los indígenas no fue una "finalidad" sino un "medio" para alcanzar, en esencia, el saqueo. Si bien coincidimos con Traverso, sugerimos matizar esta perspectiva. A título de ejemplos, Auschwitz también fue instrumental a la IG Farben, su vecina fábrica de caucho, como mano de obra esclava para su producción, así como el campo de concentración Ravensbrück, lo fue para el uso de mujeres esclavas al servicio de Siemens.

\footnotetext{
11 “(...) Césaire provocativamente señala que los europeos toleraron el nazismo y lo absolvieron, cerrando sus ojos, pues éste fue aplicado antes a gente no europea de los cuales ellos fueron responsables, toda la civilización cristiana (...)".Césaire, A. (2000). Discourse on colonialism: A poetics of anticolonialism. [Versión para Kindle]. New York: Monthly Review Press. p.18. (traducción propia). El subrayado también es propio y coincidimos con el adverbio, debido a que Césaire desconoce el factor "antisemitismo", entre otras particularidades de la solución final, a los cuales elude en su obra.
} 
Como moderador entre ellos, Traverso (2012, pp.181-183) concluye que este ejercicio de comparación, a lo sumo, "se limita a indicar algunos rasgos comunes de las violencias masivas". La complejización, no obstante, se amplifica. Agrega que según los investigadores, la Shoá podría categorizarse por fuera o ser considerada como "el punto culminante" de otros genocidios modernos. Hay quienes prefieren distinguir a los genocidios como "ordinarios" y a la Shoá como "total", por sus características “extraordinarias". Considera que "estudiar la Shoá significa enfrentarse a una serie de problemas que trascienden ampliamente el concepto de 'genocidio', y que reclaman otras categorías analíticas". Valida la unicidad de la Shoá, pero como "una síntesis de masacre colonial, depuración étnica, construcción nacional totalitaria y politicidio".

También el pensador expone el concepto de Zygmunt Bauman: "El Holocausto ha de considerarse como una prueba excepcional de las posibilidades ocultas de la sociedad moderna" (Traverso, 2010, p.207). Bauman sostiene que la Shoá no es una herida de la modernidad, sino el fruto de la modernidad. Pero Traverso (2012, p.207) problematiza la premisa anterior y la divide entre la combinación de una "violencia fría", técnica y moderna, y otra "violencia caliente", hecha de masacres tradicionales. Sugiere comparar como violencias calientes, la historia del Batallón 101 de policías reservistas en Polonia $^{12}$, las masacres japonesas de Nankín en $1937^{13}$, o las perpetradas por los norteamericanos en Vietnam. Las violencias frías de los campos de exterminio, como "dispositivo técnico", podrían compararse al lanzamiento de las bombas atómicas sobre Hiroshima y Nagasaki. A nuestro juicio esta comparación resulta vulnerable, por la sustancial diferencia, del contacto directo del victimario con las víctimas en los campos de exterminio, y la falta de contacto del victimario, al lanzar bombas desde las alturas. Más allá de las singularidades específicas de dichos genocidios, Traverso infiere que dichas comparaciones, pueden facilitar su comprensión. Resume que al haber sido

\footnotetext{
${ }^{12}$ Este episodio es uno de los ejes centrales del controvertido libro de Goldhagen, D. J. (1997). Los verdugos voluntarios de Hitler: Los alemanes corrientes y el Holocausto. Madrid: Taurus. Tercera Parte. Goldhagen es un sostenedor de "la culpa colectiva de los alemanes", motivo por el cual es cuestionado. Ver: Finchelstein, Federico. (1999). Los alemanes, el Holocausto y la culpa colectiva: El Debate Goldhagen. Prefacio por Dominick LaCapra. Buenos Aires: Eudeba. En este debate, participaron doce académicos de diferentes disciplinas. Traverso, por su parte, recoge la reconstrucción de esta historia, del historiador Christopher Browning, no de Goldhagen.

${ }^{13}$ En Nankín, otrora capital de China, en 1937, los soldados japoneses asesinaron a 200.000 ciudadanos chinos, violaron a decenas de miles de mujeres y devastaron la ciudad. Ver documental: Guttentag B. (Director). (2007). Nanking. [Documental]. Coproducción EE.UU., China, Japón: Snagfilms.
} 
reconocida la excepcionalidad de la Shoá, ésta puede servir "de modelo" para comparar otros

genocidios.

Estas reflexiones, si bien sólidas, continúan representando un severo desafío intelectual. La intensidad de cada tragedia, podría ser razonablemente vista como un acontecimiento único, según la subjetividad del historiador. Para aproximarse a la comprensión de acontecimientos tan complejos, entendemos que se ha de atravesar un significativo y eficiente proceso educativo integrador de estas historias. Lo cual exige, a su vez, un compromiso social y político desde el poder, de los países que impulsen tales objetivos. Alemania, dentro del contexto del presente trabajo, es un ejemplo de ello.

\section{Memoria e historia}

\section{a) Debate entre Martin Broszat y Saúl Friedländer}

Han debido transcurrir tres décadas desde la culminación de la guerra, para que el estudio de la Shoá adquiriese la jerarquía de estudio historiográfico. Es así que se le da un rol preponderante a la memoria como aparato historiográfico y se genera una serie encadenada de preguntas. A mero título de ejemplos: ¿cómo se construye memoria y cuál?, ¿es una herramienta subvaluada políticamente o realmente carece de legitimidad historiográfica?, ¿existe una lucha políticamente descarnada en contra de la memoria?, ¿podría la memoria de las víctimas, ser socialmente aceptada?, ¿lo fue en la sociedad alemana o fue legislada por imposición?, ¿la memoria como diagnóstico de la dimensión del Holocausto, conlleva a cierta necesidad colectiva de atenuación, o en casos extremos, de "negación"?

La serie puede ampliarse desde múltiples ángulos, pero en el centro se ubica el rol específico del historiador que le dé significado a estas complejidades. La heterogeneidad de los enemigos del nazismo, las cifras de víctimas tanto del Holocausto, como de los muertos durante el período de la segunda guerra mundial, son tan escalofriantes, que estos encares historiográficos, están predestinados a no ser concluyentes, sino incluso, dificultosamente abordados. Se ha de focalizar en acontecimientos, sin dejar de considerar el contexto. Un desafío simultaneo de micro y macro historia. 
Traverso (2012) presenta el debate entre dos historiadores con posturas disímiles al respecto: Martin Broszat y Saúl Friedländer, quienes intercambiaron un cruce epistolar en 1987. Broszat abordaba el nazismo desde el interior de la sociedad alemana, y Friedländer desde la perspectiva de las víctimas. El primer historiador participó de las Juventudes Hitlerianas en 1945, el segundo fue un sobreviviente, escondido por una familia católica durante la guerra. El debate ha de ser visto como el de dos modelos historiográficos.

Broszat, referido por Traverso (2012), constata la tendencia deplorable de aislar la historia alemana desde 1939 a 1945, y su efecto de eclipsar los intentos de comprender el nazismo. Se pretendía aprehenderla como una historia de totalitarismo, y la intención de Broszat ante sus pares, era derribar dichas barreras. ¿Cómo?, subrayando que "la suerte de los judíos no estaba en el foco de la mayoría de los alemanes, y por lo tanto, el exterminio de los judíos no debería constituir el 'único patrón' de la percepción histórica del nacionalsocialismo" (p.153). Agrega que muchos alemanes reprobaron lo sucedido en La Noche de los Cristales Rotos, en noviembre de 1938. Mediante estas explicaciones y el modelo de historicismo que propone, Broszat pretende lograr dos objetivos: el primero, relativizar los crímenes del nazismo, y el segundo, sustituir una condena global por una condena moral. En síntesis: "lograr una normalización de la conciencia histórica alemana" (Traverso, 2012, p.154).

La propuesta metodológica de Broszat, citado por Traverso (2012), consiste en eludir el aporte de la memoria como fuente de reconstrucción del pasado, pues ésta sería "un potente obstáculo moral y político contra el esfuerzo científico de la escritura de la historia" (p.155). Broszat reconoce el carácter legítimo de la memoria judía, como un recuerdo mítico, pero éste ha de quedar fuera del campo de la investigación histórica. Traverso se cuestiona acerca de cuáles son las verdaderas intenciones de Broszat, y los límites al historicismo que propone.

En tanto, Friedländer, referido por Traverso (2012), reprueba que independientemente de sus intenciones, Broszat relativiza la dimensión criminal del nazismo. Sostiene que 
ignorando los vínculos de la sociedad alemana con el nazismo, la sustrae de la "sombra de Auschwitz" (p.157). Friedländer construye a su vez, dos dimensiones para su crítica: la primera es que la postura de Broszat, ignora la monumental resistencia de sectores ("minoritarios") de la sociedad alemana que reprobaron al régimen; a su juicio, "la sociedad civil sana" (p.158) dentro de un sistema político criminal. La segunda es que el régimen nazi no habría podido perpetrar sus crímenes sin el apoyo "mayoritario" de la sociedad alemana.

Esta fase del enfrentamiento, plantea la vulnerabilidad de ambos historiadores acerca de cómo se miden, cuáles mayorías o tales minorías. Uno no puede soslayar su pasaje por las juventudes hitlerianas, el otro, haber sobrevivido en condiciones límites. Sus subjetividades parecen ser un escollo ineludible ${ }^{14}$. Friedländer, referido por Traverso (2012, p.160) no legitima al historicismo científico de Broszat, lo considera "una vana ilusión psicológica y epistemológica" (p.160). Argumenta que miles de ferrocarriles atestados con miles de judíos fueron llevados a los campos de extermino, diariamente, con la participación de miles de funcionarios alemanes. Cientos de miles de soldados alemanes tenían conocimiento directo del genocidio de los judíos, y registraron, ellos mismos, fotografías y cartas descriptivas. Sería imposible eximir a la mayor parte de la población alemana de dichos conocimientos. No obstante reconoce, que la historización del pasado reciente del nazismo, es "tan necesaria como imposible" (Traverso, 2012, p. $160)$.

Broszat, citado por Traverso (2012), sostiene que Hitler jamás habría decidido la solución final, ${ }^{15}$ de no ser por las dificultades del ejército alemán en el frente oriental. Que se trató de una "radicalización acumulativa" (p.164) en que los judíos, quienes inicialmente representaban un rol "metafórico" en la ideología nazi, "se transformaron a posteriori en una indispensable fuente legitimadora" (p.164).Friedländer convalida que en un principio, el exterminio nazi se limitaba a los judíos de los territorios

\footnotetext{
${ }^{14}$ Theodor Adorno es concluyente: "El mundo es otro después de Auschwitz". Frente a este postulado, el distanciamiento resulta no solo impotente, sino inmoral. Adorno, T. (2002). Educación para la emancipación. Editorial Morata, capítulo 5. p.29. Centro de Estudiantes del IPA (Instituto de Profesores Artigas).

${ }^{15}$ Utilizamos cursiva para este concepto, dada su especificidad y unicidad, con el fin de que no se infiera una lectura simplificada de dicho término.
} 
conquistados, pero a partir de la Conferencia de Wannsee ${ }^{16}$, se extendió a los once millones de judíos, estimados por el propio Heydrich, que habitaban toda Europa. Y contextualiza que ya desde enero de 1933, el régimen nazi provocó el éxodo de judíos, intelectuales y artistas de izquierda. Cita, entre otros, los casos de Otto Klemperer y Bruno Walter (ambos directores de filarmónicas en Berlín y Leipzig), Max Liberman (Presidente de la Academia de Artes de Prusia), y al propio Albert Einstein, quien escribió: "lo que estaba pasando en Alemania era una enfermedad psíquica de las masas" $" 17$. Luego aborda directamente la solución final en varios capítulos. Describe la matanza de treinta mil judíos del gueto de Riga, orden dada directamente por Himler, entre cuyas víctimas se encontraba el historiador judío Simón Dubnow, quien al ser recogido, supuestamente dijo: “Gente, no olviden, hablen de esto, gente; regístrenlo todo." ${ }^{18}$ Es válido citar otro archivo registrado por Friedländer:

La lucha por salvarme, es inútil... pero eso no importa, pues haré el esfuerzo hasta el final y con la confianza, que mi relato verá la luz del día cuando el tiempo sea el correcto... y la gente sabrá lo que pasó y preguntarán, ¿es verdad esto? Me adelanto a responder: No, esta no es la verdad, es solo una pequeña parte, una minúscula

\footnotetext{
16 "El 20 de enero de 1942 se celebró una reunión en una villa a la orilla del lago Wannsee. El acontecimiento es tristemente célebre por considerarse el acto más importante en la historia de la "Solución Final" (la exterminación total de los judios de Europa). El encargado de convocar el encuentro fue Reinhard Heydrich, quien citó a una serie de altos cargos del gobierno a debatir 'la cuestión judía', adjuntando la copia de autorización firmada por Hermann Göring. Dado que la reunión comenzaba al mediodía, también se anunciaba que se ofrecería 'un refrigerio'. Resulta instructivo destacar, cuando algunos se refieren a los nazis como 'una clase inferior de criminales' de escasa formación, que de las quince personas congregadas en aquella ocasión, ocho habían alcanzado el grado de doctor universitario. Los asuntos discutidos en la Conferencia de Wannsee se han recuperado, debido al ejemplar del acta levantada por Adolf Eichmann, coronel de la SS y 'experto en asuntos judíos"'”. Rees, L. (2005). Auschwitz: Los nazis y la solución final. Barcelona: Crítica, p.132.

${ }^{17}$ Friedländer, S. (2009). Nazi Germany and the jews, 1933-1945. New York: Harper Perennial. p.3. (traducción propia).

${ }^{18}$ Friedländer cita a Dubnow-Ehrlich, S. The life and world of S.M. Dubnow: Diaspora nationalism and Jewish History. (New York, 1991, pp.246-47). pp.260 y 439. (Traducción del autor).
} 
fracción de la verdad... incluso la más poderosa pluma, no podría describir la total, real y esencial verdad" ${ }^{\prime 19}$. (Traverso, 2012, pp.145-167).

Traverso escribió en el año 2007, que a lo largo del siglo XX, las ciencias sociales han tratado de separar a la "memoria" de la "historia". Y que la idea no es establecer jerarquías entre ambos conceptos, sino, por el contrario, captar su diferencia. Concluye:

La memoria es un conjunto de recuerdos individuales y de representaciones colectivas del pasado, la historia, por su parte, es un discurso crítico sobre el pasado; una reconstrucción de los hechos y acontecimientos, tendiente a su examen contextual y a su interpretación (Traverso, 2012, pp.281-282).

\section{b) Debate entre Ernst Nolte y Jürgen Habermas}

Este debate transcurre en la otrora República Federal de Alemania, entre los años 1986 y 1987. Nolte es un historiador alemán, que fue alumno de Martin Heidegger. Habermas es un sociólogo y filosofo alemán, ayudante, entre otros, de Theodor Adorno. La controversia surge a partir de un artículo escrito por Ernst Nolte, cuyo título es sugestivo: "El pasado que se niega a pasar. Un discurso que fue escrito, pero nunca pudo ser pronunciado" ${ }^{20}$. Nolte expresa, que si todo pasado pasa y este no (el nacionalsocialista de los alemanes), ello supone algo excepcional, y agrega que este pasado "se establece incluso como presente o pende sobre éste, a modo de espada justiciera" (Mann, T. Nolte, E. y Habermas, J., 2011, p.19).

No consideraremos, inicialmente, los argumentos que Nolte describe en clave de comparaciones entre fascismo y comunismo. El historiador es muy crítico con la República Democrática Alemana, en coordenadas, que en principio -y sin éxito, como veremos más adelante-, entendimos prescindibles de abordar para los fines de este

\footnotetext{
${ }^{19}$ Ibidem. Ernst, S. The Warsaw ghetto. Escrito en un escondite en 1943, en el "lado ario de Varsovia". p.285. (traducción propia).

${ }^{20} \mathrm{El}$ artículo fue escrito en idioma alemán, en el diario Frankfurter Allgemeine Zeitung, el 6 de junio 1986. Mann, T., Nolte, E. y Habermas, J. (2011). Hermano Hitler: El debate de historiadores. México D.F: Herder. Versión original del título y traducción al español, en la contratapa del libro.
} 
trabajo.

El autor le atribuye a la solución final, y a la "monstruosidad del exterminio industrial de varios millones de personas" (Mann, T. Nolte, E. y Habermas, J., 2011, p.21), la causa que erige un muro frente a otros argumentos y núcleos de verdad, que podrían poner un punto final a la discusión, o sea: ese eventual obstáculo, aleja la hipótesis de una superación respecto al pasado alemán. Nolte se cuestiona qué intereses se mantienen vigentes respecto a este estado de la cuestión. Si se trata de una lucha generacional de los jóvenes alemanes contra sus padres, o acaso entre perseguidos y descendientes por conservar privilegios. Eleva la mira e incurre en un terreno de historia social o psicosocial y sostiene: 'El discurso de 'la culpa alemana', pasa alegremente por alto el discurso de 'la culpa judía', que fue uno de los principales argumentos de los nacionalsocialistas" (Mann, et al, 2011, p.23).

Esta reflexión, apenas resguardada por un entrecomillado, es sumamente vulnerable. Pone en igualdad conceptual al término: "culpa judía”, una construcción mitológica de un imaginario ${ }^{21}$, y "culpa alemana", que debiera considerarse una responsabilidad histórica de una coyuntura específica en términos de un historicismo real, de hecho, rupturista en superlativa dimensión con el pasado alemán, como lo fue la Shoá. Responsabilidad de quiénes y cuántos y en qué grados, de eso se trata la complejidad en el análisis. Nolte justifica el argumento, pues entiende que las inculpaciones a los alemanes, provenientes de alemanes, no son sinceras, ya que los acusadores no se incluyen a sí mismos. Complejiza más aún su postura, al recordar que la solución final, distrae las realidades del contexto de época, que le significaban a los alemanes vivir una vida indigna. Problematiza esta tensión y reflexiona, si esta postura historiográfica de un pasado que no pasa, no es acaso peligrosa, en tanto pudiese revivir la identificación de los alemanes con el Tercer Reich, como lo hizo "la mayoría de ellos, entre 1935 y 1939” (Mann, T. Nolte, E. y Habermas, J., 2011, p.23). En síntesis, infiere que la

\footnotetext{
${ }^{21}$ Esta construcción, en su versión moderna de fines del Siglo XIX, se condensa en Los Protocolos de los Sabios de Sion, escrito por autor anónimo en la Rusia Zarista y publicado en París en la década de 1890. De ribetes maléficos, le atribuye un conglomerado de todas las desgracias mundiales, al "complot judío". Eco, H. (2002). Sobre Literatura. Barcelona: Océano. Capítulo: La fuerza de lo falso.
} 
pedagogía de la historia nacional, así aplicada, podría provocar en los alemanes, similares reacciones a las de aquel pasado.

Si Traverso (2012) dudaba de las verdaderas intenciones de Broszat, cuánto más se puede dudar de las de Nolte, debido al corte temporal que elige para aceptar la identificación de la mayoría de los alemanes con el nazismo. ¿Sugiere que dicha mayoría no fue acaso la que llevó a Hitler al poder en 1933 o que acaso tomaron distancia del Tercer Reich después de 1939? ¿Pretende eludir de esa forma la eventual complicidad de cierta mayoría, al menos, con la Shoá? Su historicismo en tal sentido, genera un gran silencio que debería explicar.

A esta altura de la resistencia crítica de Nolte, de jerarquizar a la Shoá como un aspecto indivisible de la historia alemana, con toda la carga moral que conlleva, el autor propone su perspectiva de cómo resolver estos dilemas historiográficos. Es entonces que derrapa a una puja que enlaza fascismo y comunismo, la cual homogeniza su posición histórica-política y de la cual, finalmente, no podemos prescindir en el presente análisis. Nolte nos retrotrae al genocidio armenio, que se originó a la "manera asiática", muy lejana a la modalidad europea, vinculándolo al encarnizado enfrentamiento alemán en el frente oriental, contra los rusos. Se pregunta qué pudo haber llevado a varones que percibieron de cerca ese enfrentamiento de "estilo asiático", a generar uno de "naturaleza aún más sanguinaria” (Mann, et al., 2011, p.27). Y profundiza, si acaso ¿no habría sido debido a la propaganda comunista que proclamaba la aniquilación de la burguesía?, ¿no se habría sentido "el propio Hitler” temeroso de sufrir un similar genocidio asiático, a sabiendas de lo acontecido en los gulags, más originarios que Auschwitz? Nolte se cuestiona si no fue el genocidio "de clase" de los bolcheviques, el predecesor lógico y fáctico del "genocidio racial” de los nacionalsocialistas (p.27).

Ante tal nivel de problematización de sus conjeturas, comprometidas con una perspectiva, quizás "contra fáctica", sin duda vulnerables historiográficamente y de alto impacto, el propio Nolte se declara cohibido de plantearse estos cuestionamientos, y confiesa que tardó mucho en atreverse a hacerlo. Acepta que las tesis combativas anticomunistas de la Guerra Fría, no encajan muy bien en la ciencia. "Pero si un 
asesinato -y no digamos un genocidio- no se puede justificar con otro asesinato, igual nos conduce al error la actitud que ve únicamente un determinado asesinato o genocidio, sin tener en cuenta a los otros" (Mann, et al., 2011, pp.25-28). Explica que el sentido que pueden encontrar las nuevas generaciones, aun "con sus innumerables tinieblas y horrores", es liberarse de "la tiranía del pensamiento colectivista". Se trata de librarse de las perspectivas de considerar a "el judío", "el ruso", “el alemán” o "el pequeño burgués". Y si ello no pudiera ser resuelto para la discusión sobre el nacionalsocialismo, a ésta se le ha de poner "un punto final”. (Mann, et al., 2011, pp.25-28)

En síntesis, la historia comparada que aplica Nolte entre nacionalsocialismo y comunismo, representa el punto de Arquímedes que sostiene su conceptualización del pasado alemán reciente. En su pensamiento, no categoriza a los sobrevivientes de la Shoá como sujetos políticos, ni de contexto ni de concepto. Este núcleo medular de su historiografía, es el que dará lugar a la reflexión más contundente de Habermas al respecto, quien acuñó el término: "uso público de la Historia" (Mann, T. Nolte, E. y Habermas, J., 2011, contratapa del texto), que exhibe las tensiones ineludibles entre olvido, memoria, responsabilidades, justicia y verdad.

Habermas dialoga entre pares y avanza formulando conclusiones entremedio, que son las que recopilaremos. Sostiene que: "la perspectiva de la liberación tan solo sería aplicable a las víctimas de los campos de concentración y no a la nación alemana como un todo" (Mann, et al., 2011, p.38). No es posible eludir la responsabilidad moral de los actos de exterminio en los campos. El colapso alemán en el frente oriental, expuesto como "la destrucción del imperio alemán”, y el exterminio de los judíos, no pertenecen a un mismo entramado. Agrega que aún designándose a Hitler como el gran responsable de la idea de solución final, "la gran masa de la población se calló la boca" (Mann, et al., 2011, p.38). Al igual que otros historiadores, Habermas se estremece ante la significativa cantidad de intelectuales que acompañaron el proceso nazi. Reniega de la postura de Nolte, que "todos los gatos son pardos" (Mann, T. Nolte, E. y Habermas, J., 2011, p.41), y que reduzca la singularidad de la Shoá, a la característica "técnica" del gaseado. 
Le recrimina a Nolte que infiera que: "Auschwitz se encoge a la dimensión de una innovación técnica y se explica a través de una 'amenaza asiática', de un enemigo que aún está en la puerta" (Mann, et al., 2011, p.43). Cita coherente en el año 1987, refiriéndose a la República Democrática Alemana aún alineada a la U.R.S.S. en esos momentos. Habermas postula que la búsqueda de una historia perdida, no es una configuración educativa abstracta, sino una necesidad política y moral a resolver, y que es dable que genere lecturas plurales, que denotan una sociedad abierta.

Al igual que Friedländer, quien no tomó en cuenta las intenciones historiográficas de Broszat, Habermas tampoco se expide en tal sentido respecto a Nolte. No obstante señala, en contrapartida al controvertido corte temporal de Nolte -por el cual entendemos legítimo subrogarnos al modelo de crítica historiográfica de Traverso (2012), tal como cuestionó las intenciones de Broszat-, una interesante periodización. Habermas refiere a varios hitos históricos, que demuestran el devenir de las complejidades en debate y su evolución en el "no dejar pasar" al pasado agobiante que padecieron los alemanes luego del nazismo (Mann, T. Nolte, E. y Habermas, J., 2011, p.64). Cita las siguientes fechas, destacando "que no llegaron a tener un efecto masivo en nuestras conciencias, hasta entrados los años 80" (p.64). Estas fueron: el 50 aniversario del 30 de enero de 1933, el 40 aniversario del 20 de julio de 1944 y el 8 de mayo de $1945^{22}$. Si bien más rigurosa y amplia que la periodización de Nolte, también ésta es selectiva y podrían considerarse otras. Desde la perspectiva del antisemitismo y la propia Shoá, a título de ejemplos: la Conmemoración de La Noche de los Cristales Rotos, la Conferencia de Wannsee o la Ocupación nazi en Hungría, que dio lugar a la matanza de 600.000 judíos húngaros en el último semestre de la guerra.

¿En qué dimensión expone Habermas el concepto uso público de la historia? Recurriendo a la "memoria", sostiene que la de las víctimas, es muy diferente a la de los criminales, y que sin esa consigna, sería muy preocupante la falta de historia y "de consideración” de la nación alemana (Mann, et al., 2011, p.68). En otros términos, el pasado no podría darse por solucionado de otra forma. La "culpa" de los antepasados,

\footnotetext{
22 Asunción de Hitler al poder, intento fallido de atentado contra Hitler y rendición alemana, respectivamente.
} 
no es transferible a las nuevas generaciones, pero la culpa personal de los criminales, queda vinculada a la responsabilidad pública de quienes no hayan intentado hacer algo en contra. La problemática radica, según Habermas, en analizar si para las nuevas generaciones, aún existe un problema de "corresponsabilidad" (p.68). Considera que esa respuesta ha de ser afirmativa y transferible de generación en generación, a los efectos de que por encima de esa herencia, los ciudadanos judíos, los hijos y nietos de los asesinados, puedan, finalmente, respirar libremente en la sociedad alemana. Ello se lograría mediante un recuerdo solidario con lo irreparable, abordando con reflexiones analíticas a las tradiciones alemanas, de forma tal, que le den un nuevo sentido a la sociedad. Y finaliza con la siguiente reflexión: "No se trata de discusiones científico teóricas, sino del "uso público de la historia"” (p.75).

El dilema queda, pues, abierto a las múltiples tensiones que devienen de los cruces entre memoria y olvido. Habermas desarrolló dicha complejidad en sus pensamientos y postulados, legando al menos una certeza al respecto, y es que ambos conceptos están integrados en la matriz del uso público de la historia, por lo cual éste nunca será neutro.

\section{Reflexiones finales}

\section{a) En torno a los alemanes}

Las victimas deben vivir y sobrevivir en la sociedad, donde se ha de discutir y renovar la construcción de la memoria. Pertenezcan al colectivo y al país que fuese. A partir de ello, son muchas más las preguntas abiertas que las respuestas. En el caso concreto del campo de este trabajo: $¿$ se trata de una lucha entre memoria dominante versus memoria de las víctimas? Lyotard, cita que los nazis quisieron borrar toda evidencia y huella de sus exterminios. La consigna era que nada fuese consignado. La solución debía ser final. Un crimen perfecto que alegaría inocencia por falta de pruebas. O sea, una política del olvido absoluta y absurda, ya que su celo y ensañamiento la evidencian como "extra política". La "política de exterminio", excede a la política. (Lyotard, 1995, p.35)

Sostenemos que la Shoá no ha de verse solamente como un "problema judío" o exclusivo de los alemanes -sin duda alguna los mayúsculos responsables-, sino de la 
humanidad y subsiste como un paradigma no resuelto, tanto "por acción" ${ }^{23}$," como "por omisión”. Justificaremos estas reflexiones mediante el siguiente caso:

Samuel Artur Zygelbojm, de origen polaco (1895-1943), fue dirigente del Bund (Partido Judío Socialista), e intentó informar al mundo sobre el exterminio masivo de judíos durante el Holocausto. Cuando estalló la Segunda Guerra Mundial en septiembre de 1939, fue tomado como rehén por los alemanes en Varsovia. Después de liberado, participó en la organización de una célula de resistencia del Bund. Temiendo ser detenido debido a sus actividades clandestinas, huyó a Europa occidental, donde informó en una reunión de la Internacional Socialista sobre la persecución del judaísmo polaco. En septiembre de 1940 abandonó Francia y se dirigió a Nueva York. En 1942 regresó a Europa y fue nombrado miembro del Consejo Nacional del Gobierno Polaco en el Exilio, con sede en Londres. Cuando Zygelbojm recibió los informes de las masacres realizadas por los alemanes en Polonia, imploró a los gobiernos del mundo libre que lanzaran operaciones de salvamento en las regiones ocupadas por los nazis. En mayo de 1942 recibió un nuevo informe del Bund en Varsovia sobre el exterminio masivo del judaísmo polaco. Este fue uno de los primeros reportes oficiales que definió el alcance de la matanza y proporcionó nombres y ubicación de campos de exterminio. Zygelbojm habló el 2 de junio de 1942 en una emisión radial de la BBC, para difundir las horrorosas noticias y clamar para que se detuviese la masacre. En octubre, un representante de la resistencia polaca le trajo un mensaje en que le rogaban que adoptara medidas inmediatas, para salvar a sus hermanos judíos. Se dirigió a todos aquellos que tenían poder para hacer algo, incluidos el Primer Ministro Churchill y el Presidente Roosevelt. Nadie respondió a su clamor. En mayo de 1943, informado de que los últimos judíos de Varsovia, entre ellos su esposa y su hijo de 16 años, habían sido asesinados, Samuel Zygelbojm se suicidó como acto de desesperación y protesta por la apatía mundial ante el destino de los judíos (Yad Vashem, Enciclopedia del Holocausto).

\footnotetext{
${ }^{23}$ Los códigos de silencio y ocultamiento de crímenes atroces, se reiteran como una constante por parte de los perpetradores de los genocidios, no solo en el caso de los nazis.
} 


\section{b) En torno a la memoria como recurso historiográfico y la postura del historiador}

Los siguientes conceptos, presentados en contextos globales, son igualmente pertinentes: ¿Se le puede poner punto final a la memoria? ¿Cómo y quién establece los antónimos más ajustados al término "olvido": memoria, justicia, futuro, acaso: “educación”? Vistas las complejas comparaciones entre genocidios, siempre al acecho y en cualquier lugar, ¿existen garantías de no repetición? ¿Son divisibles los conceptos de justicia, verdad y memoria, o reductibles a estrategias políticas y sociales de coyuntura? Pregunta final: ¿Es la reconciliación el gran objetivo? Si así lo fuese, ¿se puede encontrar reconciliación salteándose los desafíos antes expuestos?

Una alineación similar a este propósito historiográfico inspirado en Enzo Traverso, la podemos encontrar en el historiador Marc Bloch, en su libro Introducción a la historia, escrito en 1949, en su caso, como relator en tiempo real post Segunda Guerra Mundial. A modo de una muy austera síntesis, destacamos algunos conceptos útiles para las problematizaciones desarrolladas en el presente trabajo.

“Pocas ciencias están obligadas a usar simultáneamente tantas herramientas dispares. Es que los hechos humanos son de lo más complejos, y el hombre se coloca en el extremo de la naturaleza (...) Aun suponiendo una gran cantidad de conocimientos en los investigadores mejor provistos, éstos hallarán siempre y muy de prisa, sus límites”. (Bloch, 1949, pp.70-71)

'Una palabra domina e ilumina nuestros estudios: 'comprender'. No digamos que el buen historiador está por encima de las pasiones”. (Bloch, 1949, p.140) 


\section{Bibliografía}

Arendt, H. (1978). Una revisión de la historia judía y otros ensayos. Buenos Aires: Paidós.

Arendt, H. (2010). Eichmann en Jerusalén. Barcelona: de Bolsillo. Bauman, Z. (1989). Modernidad y Holocausto. Madrid: Sequitur. Bloch, M. (1949). Introducción a la historia. México D.F: Fondo de Cultura Económica.

Broszat, M. y Friedländer, S. De la historización del nacionalsocialismo, Intercambio de cartas, Munich, 20 de setiembre de 1987. Recuperado de http://www.comisionporlamemoria.org/investigacionyensenanza/pdf_biblioteca/De\%20 la\%20historizaci\%C3\%B3n\%20del\%20nacionalismo,\%20Intercambio\%20de $\% 20$ cartas -\%20Broszat-\%20Fried1\%C3\%A4nder.pdf

Césaire, A. (2000). Discourse on colonialism: A poetics of anticolonialism. [Versión para Kindle]. New York: Monthly Review Press.

Finchelstein, F. (1999). Los alemanes, el holocausto y la culpa colectiva: El debate Goldhagen. Buenos Aires: Eudeba.

Finchelstein, F. (2010). Fascismo trasatlántico: Ideología, violencia y sacralidad en Argentina y en Italia, 1919-1945. Buenos Aires: Fondo de Cultura Económica.

Friedländer, S. (2009). Nazi Germany and the jews 1933-1945. New York: Harper Perennial.

Fritzsche, P. (2006). De alemanes a nazis 1914-1933. Buenos Aires: Siglo XXI.

Gentile, E. (2001). La vía italiana al totalitarismo: Partido y Estado en el régimen fascista. Buenos

Aires:

Siglo XXI. 
Goldhagen, D. J. (1997). Los verdugos voluntarios de Hitler: Los alemanes corrientes y el Holocausto.

Madrid:

Taurus.

Lyotard, J. F. (1995). Heidegger y los judíos. Buenos Aires: La Marca. Mann, T., Nolte, E., y Habermas, J. (2011). Hermano Hitler: El debate de los $\begin{array}{llll}\text { historiadores. } & \text { México } & \text { D.F }\end{array}$

Miranda, L. (2008?). Entrevistas sobre el nazismo: Robert Gellately y Peter Fritzsche "Los alemanes se sentían cómodos en el seno del Tercer Reich". Recuperado de https://www.academia.edu/732959/Entrevistas_sobre_el_nazismo_Robert_Gellately_y_ Peter_Fritzsche

Mosse, G. (2007). La nacionalización de las masas: Simbolismo político y movimientos de masas en Alemania desde las guerras napoleónicas hasta el Tercer Reich. Buenos $\begin{array}{lll}\text { Aires: } & \text { Siglo XXI. }\end{array}$

Sternhell, Z., Sznajder, M. \& Asheri, M. (1994). El nacimiento de la ideología fascista. Madrid: Siglo XXI.

Traverso, E. (2012). La historia como campo de batalla: Interpretar las violencias del siglo XX. Buenos Aires: Fondo de Cultura Económica.

Yad Vashem, (2004). Escuela Internacional para el Estudio del Holocausto, Enciclopedia del Holocausto. Jerusalén: Nativ Ediciones.

Yerushalmi, Y., Loraux, N., Mommsen, H., Milner, J.C. y Vattimo, G. (1989). Usos del olvido. Buenos Aires: Nueva Visión. 